\title{
Predicting short-term electricity demand through artificial neural network
}

\section{Autores}

Amelec Viloria, Jesús García Guliany, Noel Varela, Omar Bonerge Pineda Lezama, Hugo Hernández Palma, Lesbia Valero, Freddy Marín-González

\begin{abstract}
Forecasting the consumption of electric power on a daily basis allows considerable money savings for the supplying companies, by reducing the expenses in generation and operation. Therefore, the cost of forecasting errors can be of such magnitude that many studies have focused on minimizing the forecasting error, which makes this topic as an integral part of planning in many companies of various kinds and sizes, ranging from generation, transmission, and distribution to consumption, by requiring reliable forecasting systems.

Palabras clave

Primary feeder, Demand short-term electricity prognosis, Neural networks, Forecast accuracy.
\end{abstract}

